Supporting Information for

\title{
"Dual-Template"-Directed Synthesis of Bowl-Shaped Mesoporous Platinum Nanostructures
}

Hao Lv, ${ }^{\dagger} \S$ Xin Chen, ${ }^{\ddagger}$, Cheng Fu, ${ }^{\dagger}$ Peiliang She,${ }^{\dagger}$ Dongdong Xu ${ }^{\dagger}$ and Ben Liu ${ }^{\dagger, *}$

$\dagger$ Jiangsu Key Laboratory of New Power Batteries, Jiangsu Collaborative Innovation Center of Biomedical Functional Materials, School of Chemistry and Materials Science, Nanjing Normal University, Nanjing 210023, China.

E-mail: ben.liu@ njnu.edu.cn

${ }^{\ddagger}$ ME Genomics Inc., Software Industry Base, Shenzhen, China

${ }^{\S} \mathrm{H}$. Lv and X. Chen contributed to this work equally. 


\section{Materials and chemicals}

Potassium tetrachloroplatinate $\left(\mathrm{K}_{2} \mathrm{PtCl}_{4}, 98\right.$ wt. \%), Pluronic F127, Pluronic P123, dioctadecyldimethylammonium chloride (DODAC), dicetyldimonium chloride, dioctyldimethylammonium chloride, didodecyldimethylammonium chloride, and ascorbic acid (AA) were obtained from Alfa Aesar. Nafion solution and commercial Pt/C catalyst were purchased from Sigma-Aldrich. Hydrochloric acid (HCl) and sodium hydroxide $(\mathrm{NaOH})$, were obtained from Sinopharm Chemical Reagent Co. Ltd. (Shanghai). All the reagents are of analytical reagent grade and used without further purification. Deionized $\mathrm{H}_{2} \mathrm{O}$ with the resistivity of $18.25 \mathrm{~m} \Omega$ was used in all experiments.

\section{Synthesis of the Pt bowl-shaped mesoporous nanostructures (BMSs)}

Pt BMSs were obtained through an aqueous surfactant-templated synthetic route at $50{ }^{\circ} \mathrm{C}$, in which $\mathrm{K}_{2} \mathrm{PtCl}_{4}$, DODAC and AA are served as the metal precursor, the "dual-template" surfactant and reducing agent, respectively. Typically, $0.5 \mathrm{mg}$ of DODAC was totally dissolved in $5 \mathrm{~mL}$ of co-solvents containing $4.5 \mathrm{~mL}$ of deionized $\mathrm{H}_{2} \mathrm{O}$ and $0.5 \mathrm{~mL}$ of ethanol, followed by the addition of $0.3 \mathrm{~mL}$ of $10 \mathrm{mM} \mathrm{K}_{2} \mathrm{PtCl}_{4}$. After the above solution was incubated at $50{ }^{\circ} \mathrm{C}$ for $30 \mathrm{~min}, 0.5 \mathrm{~mL}$ of freshly prepared AA $(0.4 \mathrm{M})$ was injected. The color of the solution gradually evolved into dark brown with $60 \mathrm{~min}$, indicating the formation of the Pt BMSs. Subsequently, the product was collected by centrifuged and washed with ethanol/ $/ \mathrm{H}_{2} \mathrm{O}$ for several times. Besides, the Pt BMSs with different diameters were synthesized in the different $\mathrm{pH}$ values in the range of 1.21 and 3.18 by adding $\mathrm{HCl}$ and $\mathrm{NaOH}$, while Pt BMS nanochains were obtained by changing the molar ratios of $\mathrm{K}_{2} \mathrm{PtCl}_{4} / \mathrm{DODAC}$ (between 1.5/1 and 10/1). For comparis on, other $\mathrm{Pt}$ nanostructures were synthesized in the similar procedures but using different kind of the surfactants.

\section{Electrochemical hydrogen evolution reaction (HER)}

Electrocatalytic EOR were tested on the CHI 660E electrochemical analyzer at $25{ }^{\circ} \mathrm{C}$ with a rotating disk electrode (RDE, $0.237 \mathrm{~cm}^{2}$ ) connected to an Autolab PGSTAT302N electrochemical workstation. Besides, a carbon rod and silver chloride electrode were used as the counter electrode and the reference electrode, respectively. To prepare the catalysts ink, $1 \mathrm{mg}$ of the Pt BMSs were first mixed with $4 \mathrm{mg}$ of Vulcan XC72 , and then added into $0.8 \mathrm{~mL}$ of ethanol and $0.2 \mathrm{~mL}$ of $\mathrm{H}_{2} \mathrm{O}$. Then, $50 \mu \mathrm{L}$ of Nafion solution was added and sonicated for $30 \mathrm{~min}$. After that, $6.0 \mu \mathrm{L}$ of fresh-prepared ink solution was dropped on the RDE electrode and dried at $40{ }^{\circ} \mathrm{C}$ before the test. Linear sweep voltammetry (LSV) curves were obtained at $\mathrm{N}_{2^{-}}$ saturated $0.5 \mathrm{M} \mathrm{H}_{2} \mathrm{SO}_{4}$ with a scan rate of $5 \mathrm{mV} \mathrm{s}^{-1}$ and rotation speed of $1600 \mathrm{rpm}$ (5\% IR compensation), while cyclic voltammetry $(\mathrm{CV})$ was collected at $\mathrm{N}_{2}$-saturated $0.5 \mathrm{M} \mathrm{H}_{2} \mathrm{SO}_{4}$ with a scan rate of $50 \mathrm{mV} \mathrm{s}^{-1}$. All reported potentials in this work were referenced to the reversible hydrogen electrode (RHE). 
Electrochemically active surface areas (ECSAs) were calculated from the CV curves according to the following equation:

$$
\mathrm{ECSA}=\frac{\mathrm{Q}}{C \times m}
$$

Where Q, C and $\mathrm{m}$ are the Coulombic charge of the hydrogen ads orption peak area, the hydrogen adsorption constant $\left(\mathrm{C}_{\mathrm{Pt}}=2.1 \mathrm{C} \mathrm{m}^{-2}\right)$, the mass of the catalyst, respectively.

\section{Characte rizations}

Scanning electron microsc opy (SEM) was performed using JEOL JSM-7800F with a landing energy of $5 \mathrm{kV}$. SEM samples were prepared by casting a suspension of the samples (in ethanol) on a piece of silica wafer. Transmission electron microscopy (TEM) was carried out using a JEOL 2010 transmission electron microscope with an accelerating voltage of $200 \mathrm{kV}$. Images were recorded with a Gatan CCD camera (resolution 4000 x 2700 pixels, pixel size 9 × $9 \mu \mathrm{m}$ ). HAADF-STEM was taken on FEI, Talos F200X apparatuses at an accelerating voltage of $200 \mathrm{kV}$, which are equipped with STEM and EDS detectors for ele mental mapping analysis. TEM and STEM samples were prepared by casting a suspension of the samples on a carbon coated copper grid (300 mesh). X-ray diffraction patterns were recorded on powder samples using a D/max $2500 \mathrm{VL} / \mathrm{PC}$ diffractometer (Japan) equipped with graphite-monochromatized $\mathrm{Cu} \mathrm{K} \alpha$ radiation in $2 \theta$ ranging from $0.8^{\circ}$ to $4^{\circ}$ (for low-angle XRD) and from $10^{\circ}$ to $95^{\circ}$ (for wide-angle XRD), respectively. 


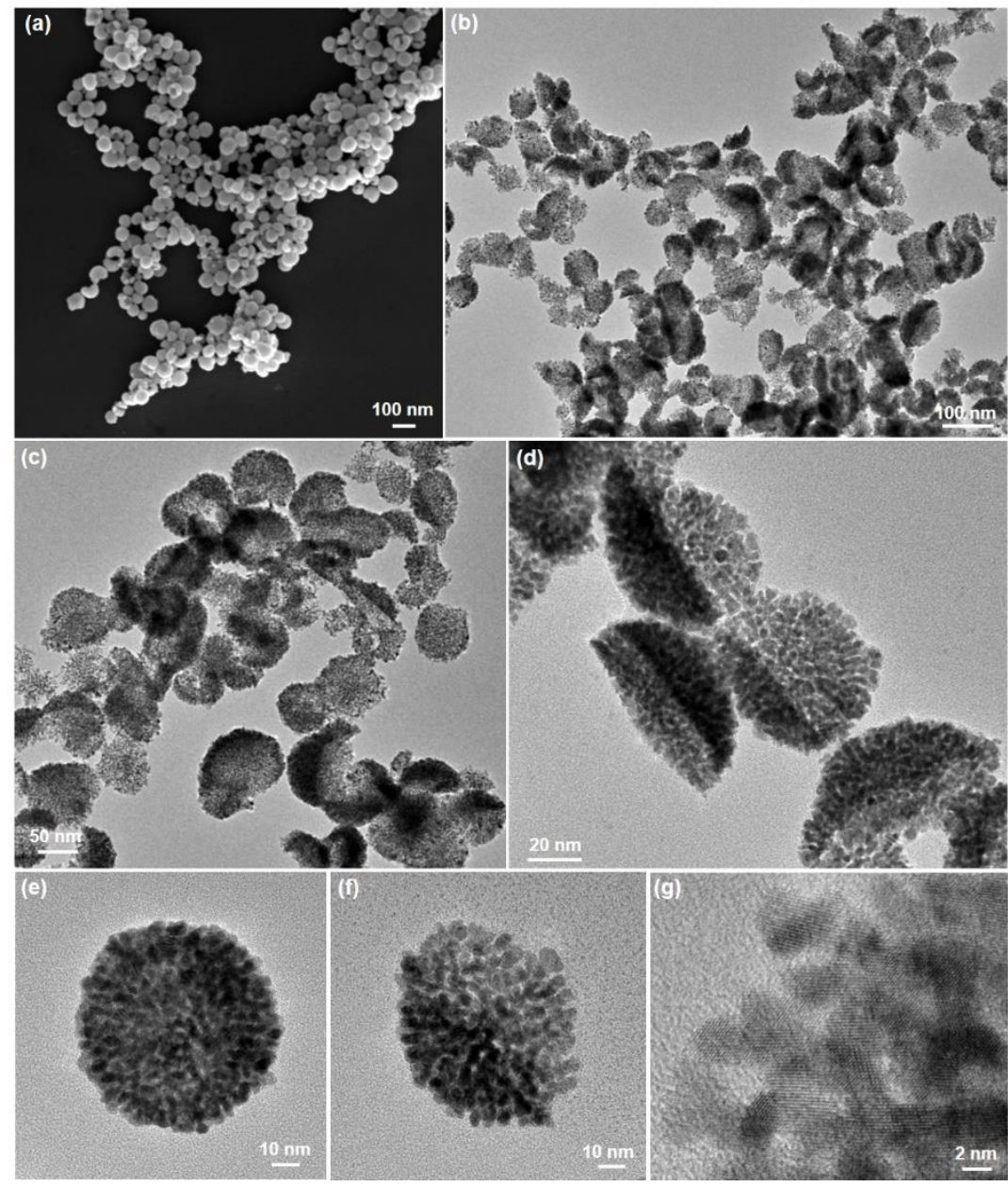

Figure S1. Structural characterizations of the Pt BMSs. (a) SEM and (b-g) TEM images with different magnifications of the PtBMSs, indicating a high uniformity, dispersity and purity.

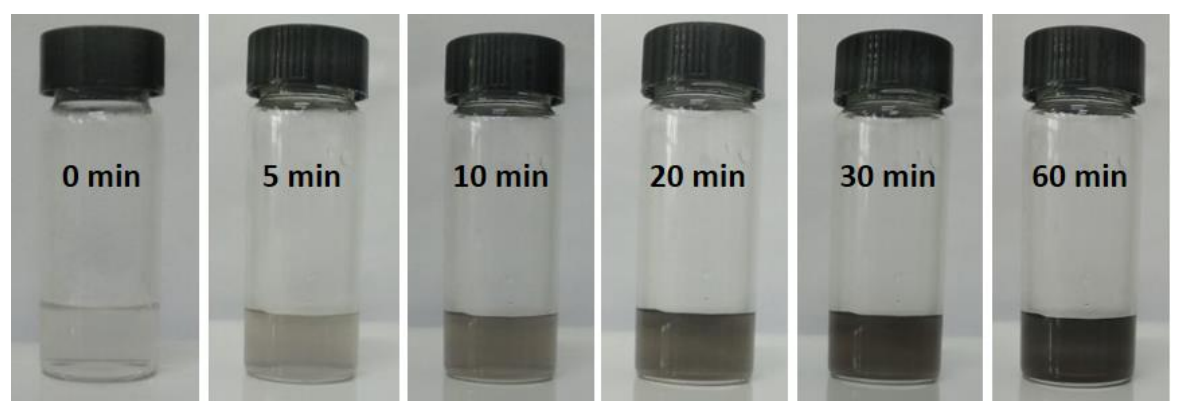

Figure S2. The color evolution of the reaction solution during the synthes is of the Pt BMSs. The reaction time is $0,5,10,20,30$, and 60 min, respectively. 

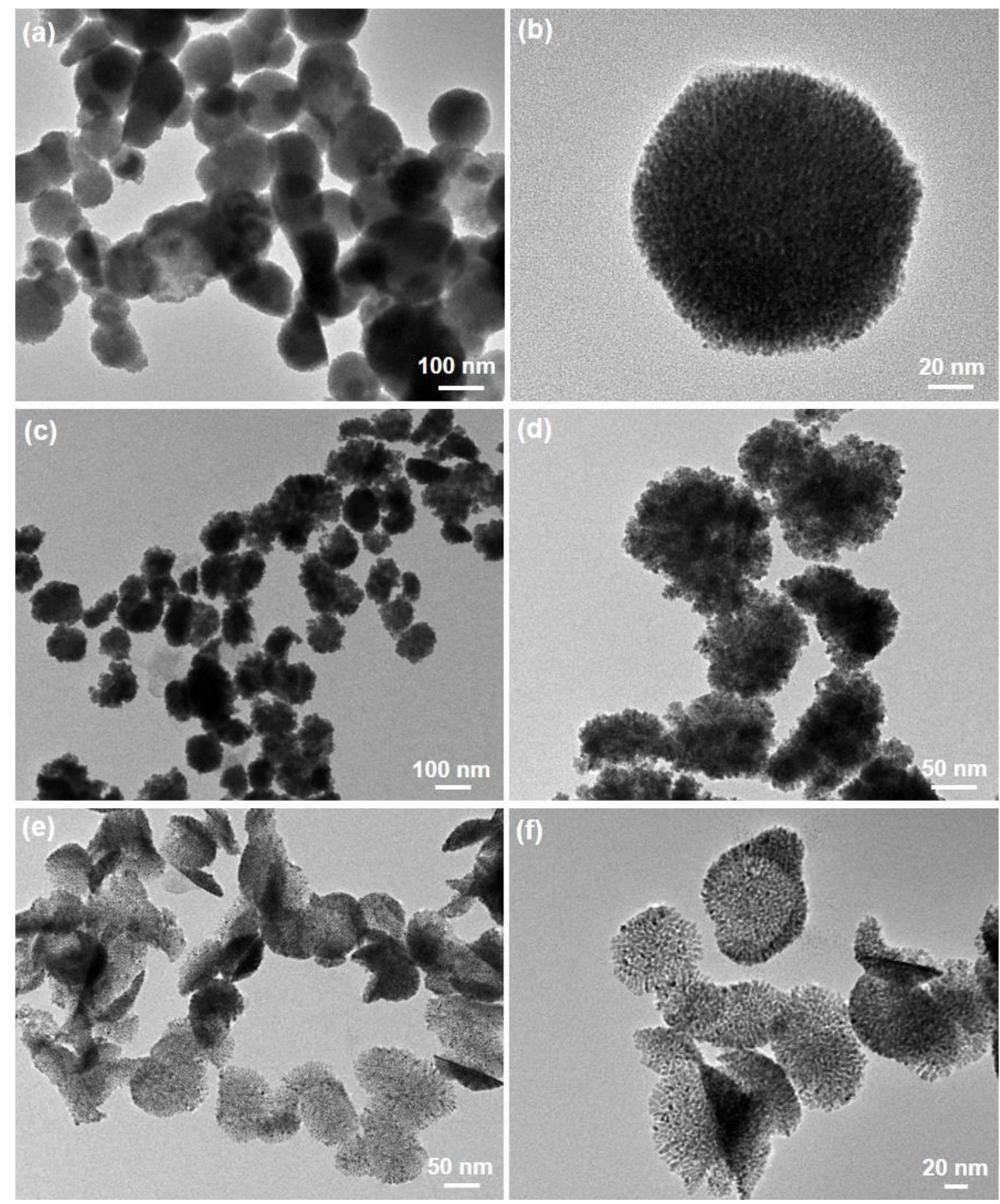

Figure S3. Structural control of the Pt nanostructures by the surfactants. TEM images of the $\mathrm{Pt}$ nanostructures synthesized with the surfactant of $(\mathrm{a}, \mathrm{b})$ dioctyldimethylammonium chloride $\left(\mathrm{C}_{8}\right),(\mathrm{c}, \mathrm{d})$ didodecyldimethylammonium chloride $\left(\mathrm{C}_{12}\right)$, and $(\mathrm{e}, \mathrm{f})$ dicetyldimonium chloride $\left(\mathrm{C}_{16}\right)$. 

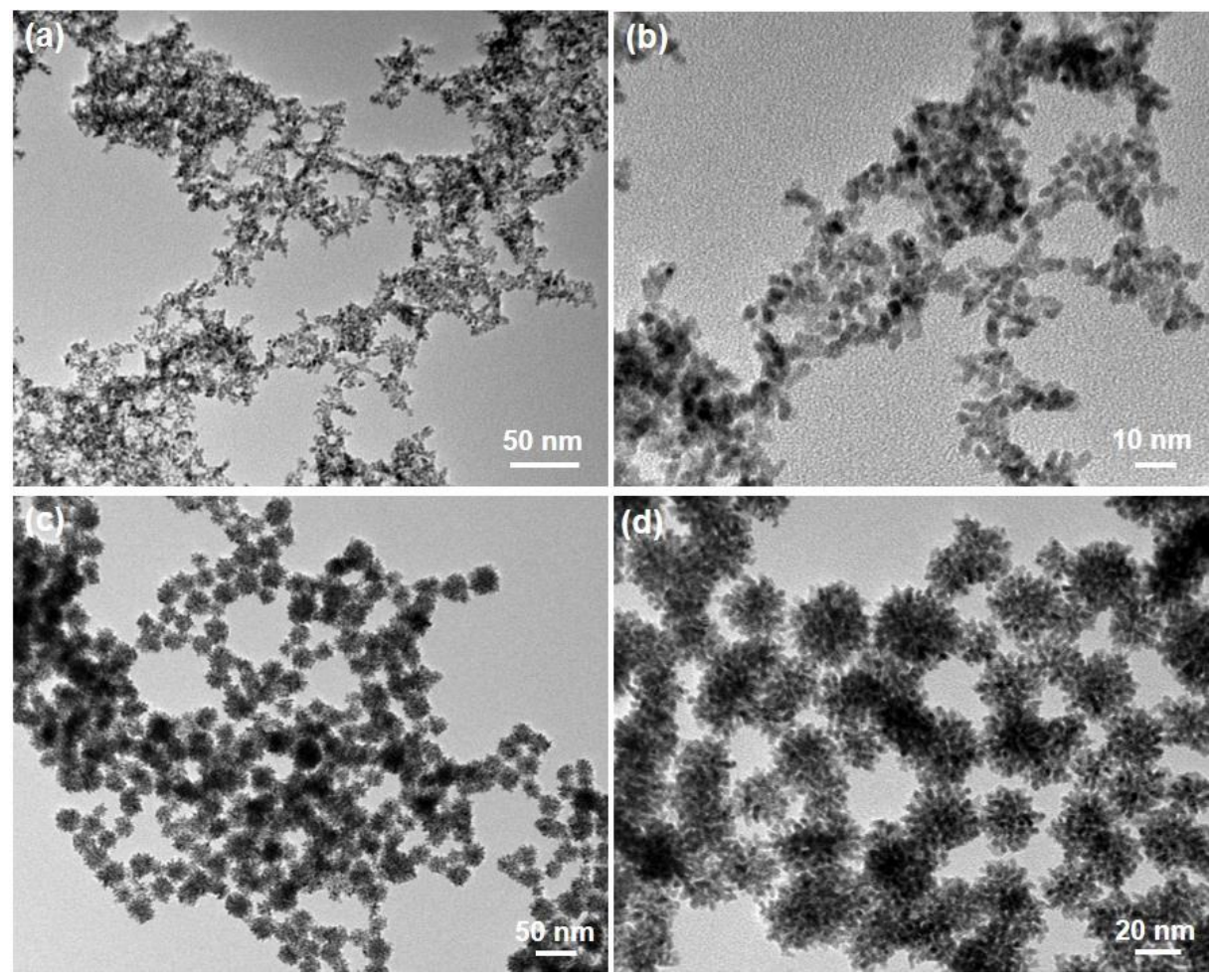

Figure S4. TEM images of the Pt nanostructures synthesized with the polymer template of (a,b) Pluronic P123 and (c, d) F127. Only mesoporous nanospheres were obtained, indicating the disability of Pluronic P123 and F127 for the formation of vesicle micelles in this synthetic conditions. 

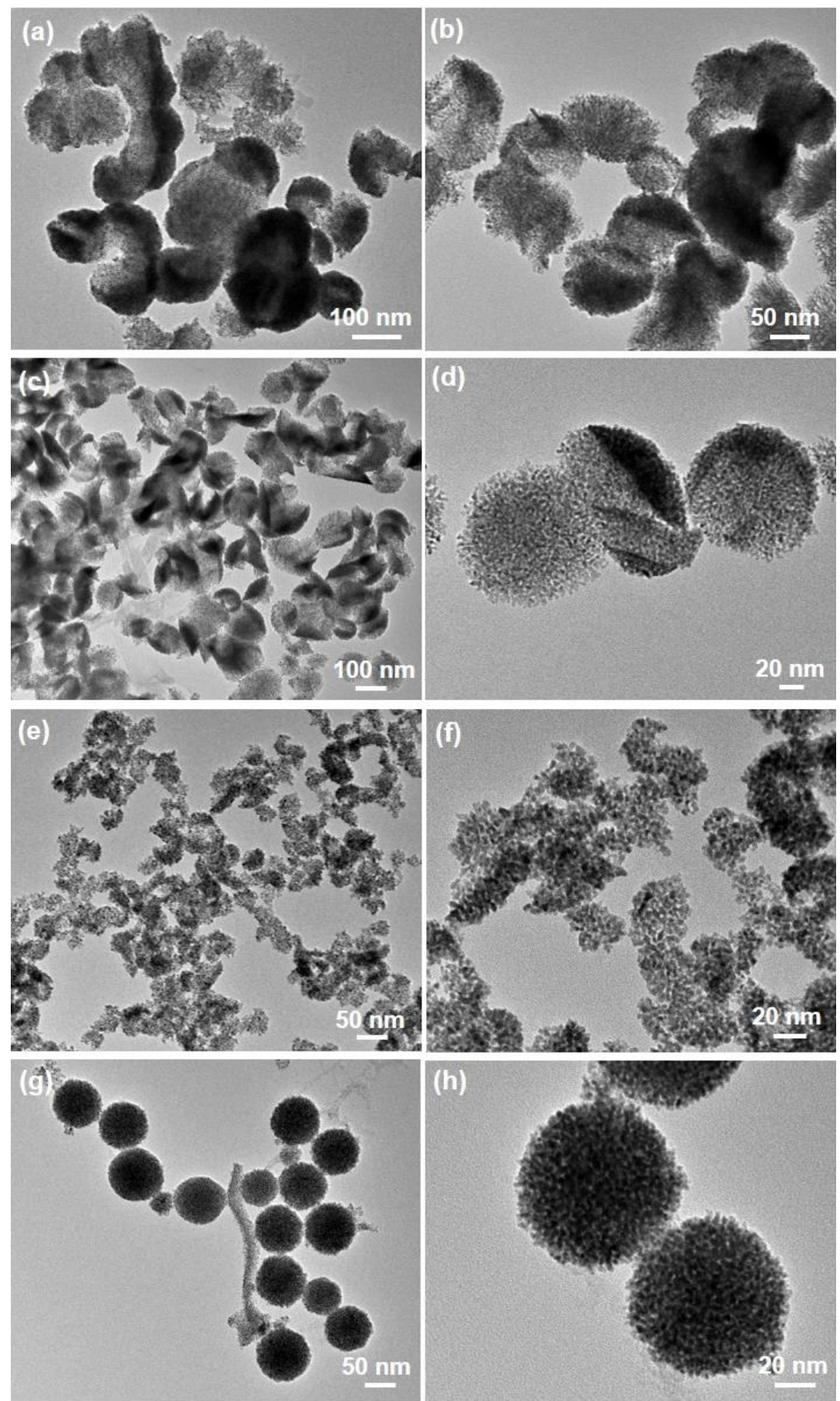

Figure S5. The effect of ethanol as the co-solvent in directing the Pt nanostructures. TEM images of the Pt nanostructures synthesized with the ethanol content of (a, b) $0 \mathrm{~mL}$, (c, d) $0.2 \mathrm{~mL}$, (e, f) $1 \mathrm{~mL}$, and (g, h) $2.5 \mathrm{~mL}$. The total volume of $\mathrm{H}_{2} \mathrm{O}$ /ethanol co-solvent for the synthesis is $5 \mathrm{~mL}$. 

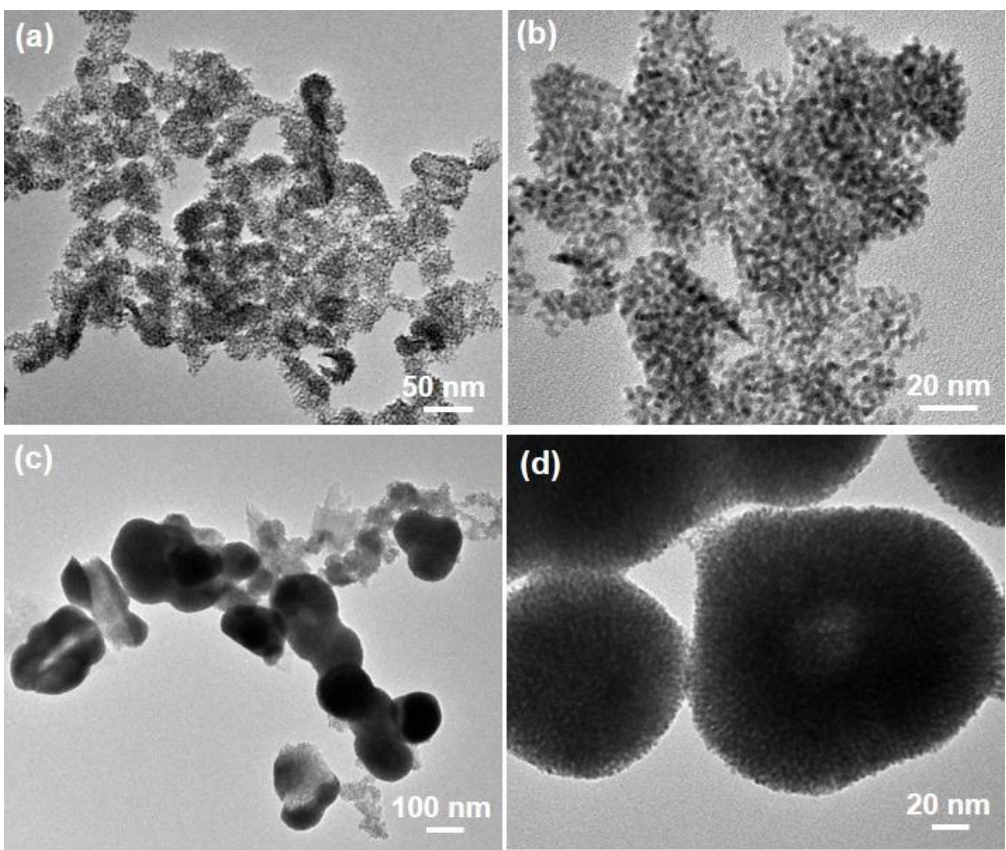

Figure S6. The effect of $\mathbf{p H}$ values in controlling the Pt nanostructures. Typical TEM images of the Pt nanostructures synthesized in a low $\mathrm{pH}$ of $(\mathrm{a}, \mathrm{b}) 1.21$ and high $\mathrm{pH}$ of $(\mathrm{c}, \mathrm{d}) 3.18$.
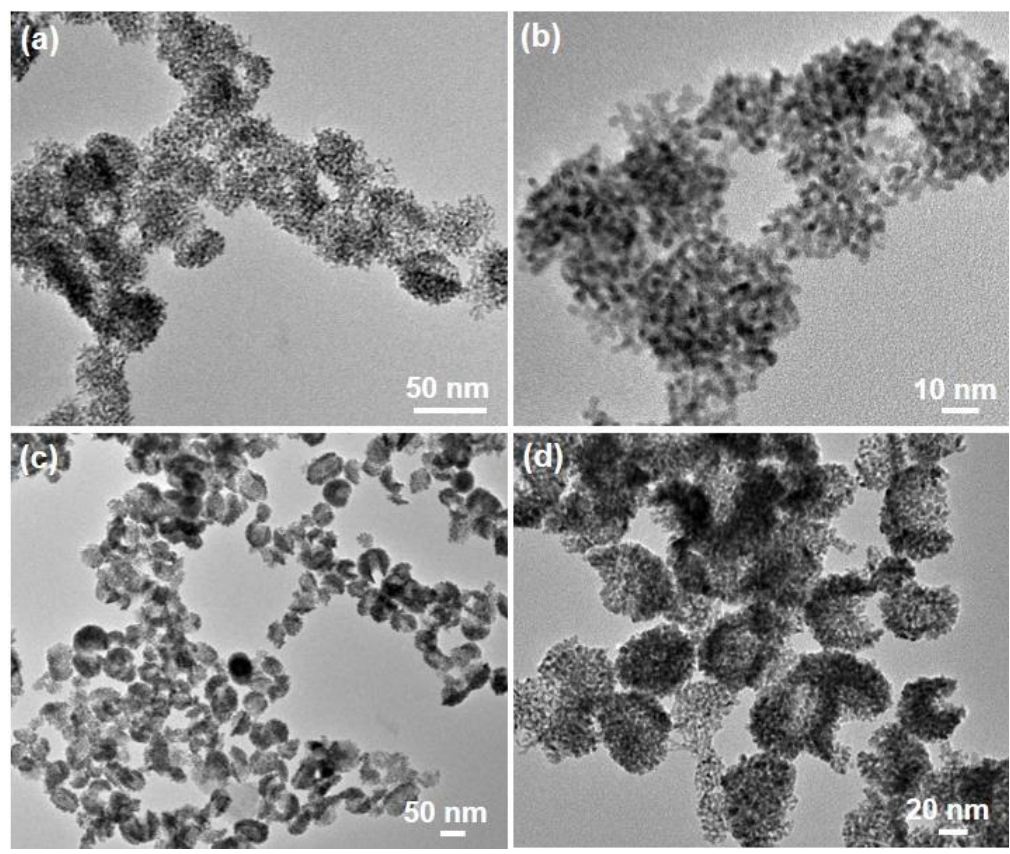

Figure S7. The effect of DODAC/PtCl ${ }_{4}^{2-}$ molar ratio in controlling the Pt nanostructures. Typical TEM images of the $\mathrm{Pt}$ nanostructures synthesized with the low $\mathrm{PtCl}_{4}{ }^{2-} / \mathrm{DODAC}$ molar ratio of $(\mathrm{a}, \mathrm{b}) 1.5 / 1$ and $(\mathrm{c}, \mathrm{d})$ 2.5/1. 

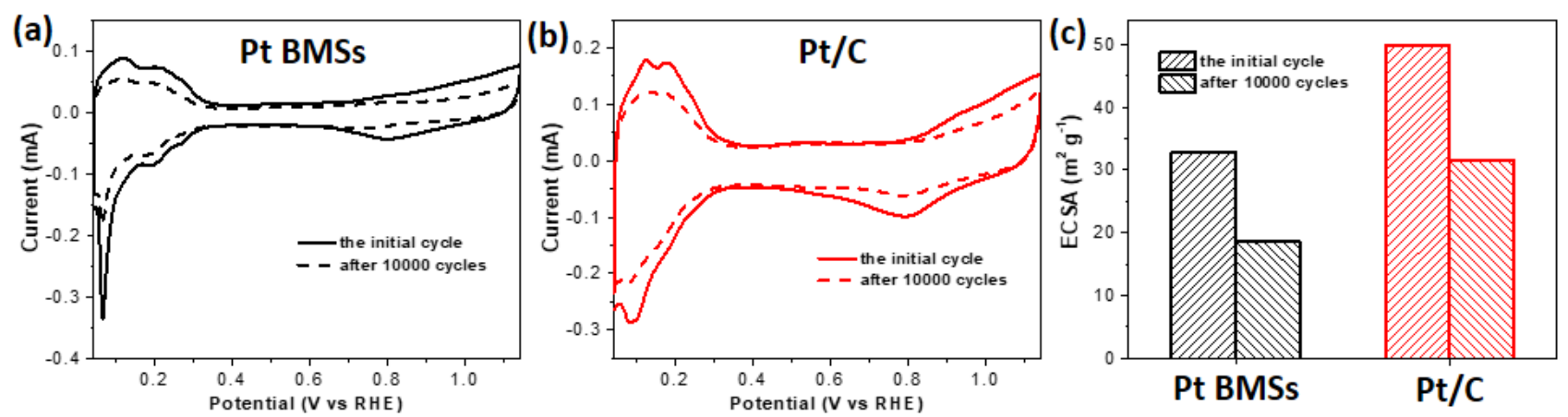

Figure S8. (a, b) Cyclic voltammetry (CV) curves and (c) corresponding ECSAs of the Pt BMSs and commercial Pt/C catalyst collected in $\mathrm{N}_{2}$-saturated $0.5 \mathrm{M} \mathrm{H}_{2} \mathrm{SO}_{4}$ solution before and after repeating $\mathrm{CV}$ scans of 10000 cycles.

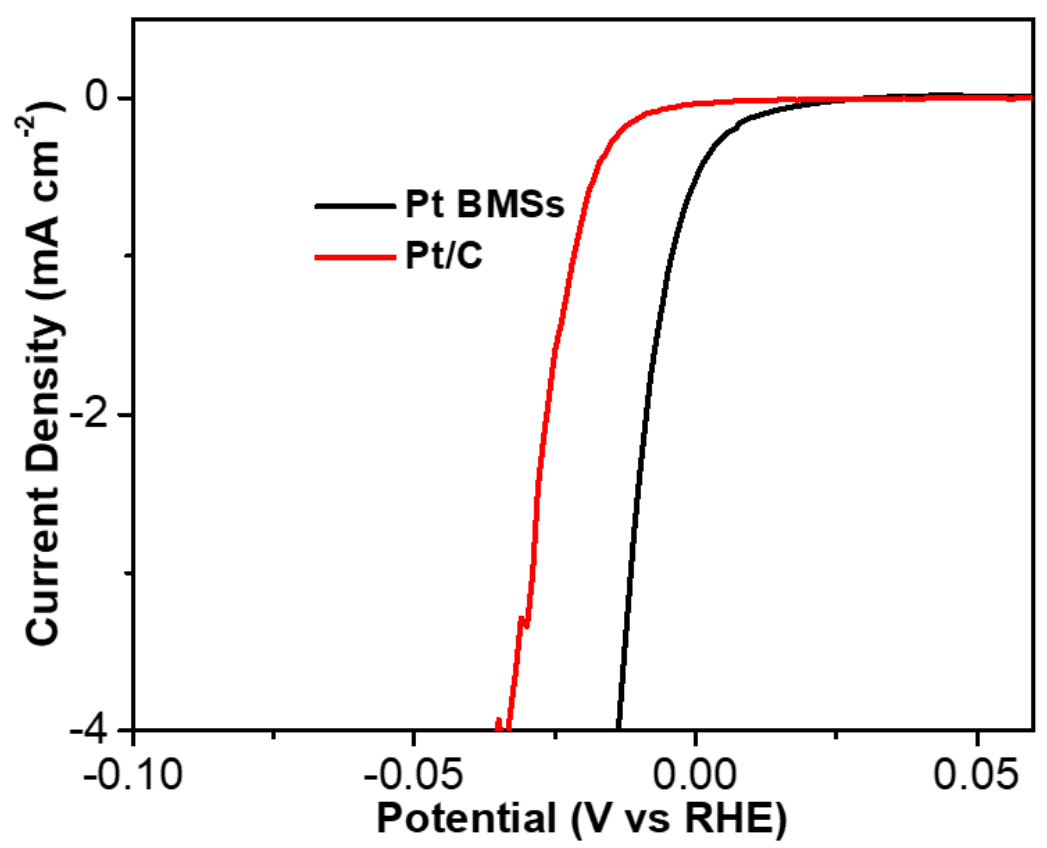

Figure S9. LSV curves of the Pt BMSs and commercial Pt/C catalyst normalized to the ECSAs. 

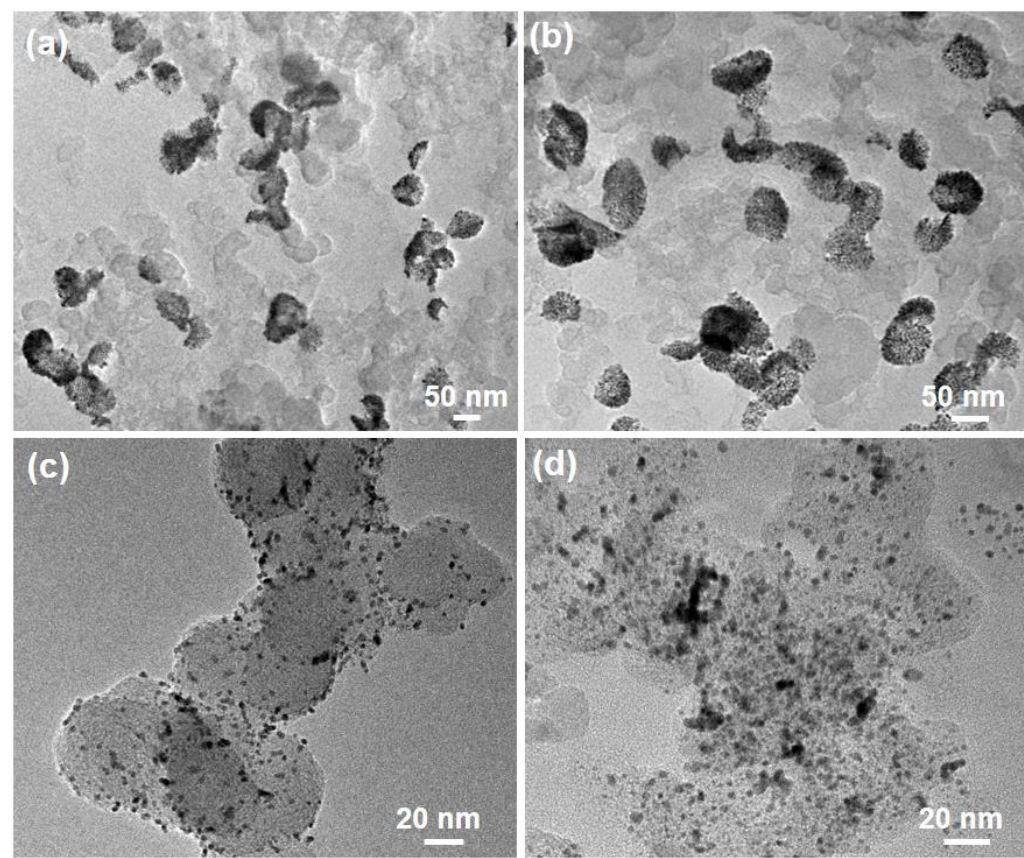

Figure S10. HER stability of the Pt BMSs and Pt/C catalyst. TEM images of (a, b) Pt BMSs and (c, d) Pt/C catalyst (a, c) before and (b, d) after repeating CV scans of 10000 cycles. 